\title{
Cidan inhibits liver cancer cell growth by reducing COX-2 and VEGF expression and cell cycle arrest
}

\author{
NAN LI $^{1 *}$, DONGHAI ZHENG ${ }^{2 *}$, JIE XUE $^{1 *}$, WEIXING GUO ${ }^{1}$, JIE SHI $^{1}$, JUXIAN SUN $^{1}$, \\ CHONGDE LU ${ }^{1}$, WEIDA ZHENG ${ }^{2}$, MENGCHAO WU $^{1}$ and SHUQUN CHENG ${ }^{1}$ \\ ${ }^{1}$ Department of Hepatic Surgery VI, Eastern Hepatobiliary Surgery Hospital, Second Military Medical University, \\ Shanghai 200438; ${ }^{2}$ Beijing Oncology Hospital Of Weida TCM, Beijing 100023, P.R. China
}

Received January 23, 2014; Accepted June 4, 2014

DOI: $10.3892 / \mathrm{etm} .2015 .2351$

\begin{abstract}
Cidan is a traditional Chinese medicine formula that has been used for $>10$ years as an antitumor drug. In the present study, the antitumor effect of cidan on hepatocellular carcinoma (HCC) and the underlying molecular mechanisms were investigated. A total of 372 patients with primary HCC, as confirmed by pathological examination in the Eastern Hepatobiliary Surgery Hospital and Beijing Oncology Hospital of Weida TCM, were prospectively enrolled in the study. In total, 92 patients were treated with cidan capsules for three months postoperatively, while 280 patients served as controls. The efficacy of cidan was analyzed by monitoring associated symptoms and liver function tests, including measuring the levels of $\alpha$-1-fetoprotein, $\alpha$-L-fucosidase, alkaline phosphatase, alanine aminotransferase, aspartate aminotransferase and $\gamma$-glutamyl transferase. In addition, in vivo analysis was performed using mice Hepa1-6 xenograft models, while in vitro studies were performed with SMMC-7721 and CSQT-1 cells; this included cidan-dependent cell viability and migration assays, cell cycle analyses and the evaluation of cidan effects on cyclooxygenase-2 (COX-2) and vascular endothelial growth factor (VEGF) mRNA transcription rates using quantitative polymerase chain reaction. The postoperative two-year overall survival (77 and 58\% for the cidan and control groups, respectively; $\mathrm{P}<0.01$ ) and disease-free survival (36 and 24\% for the cidan and control groups, respectively; $\mathrm{P}<0.01)$ rates were superior in the cidan-treated group when compared with the control. In addition, the size and weight of the tumor xenografts in
\end{abstract}

Correspondence to: Professor Shuqun Cheng, Department of Hepatic Surgery VI, Eastern Hepatobiliary Surgery Hospital, Second Military Medical University, 225 Changhai Road, Shanghai 200438, P.R. China

E-mail: chengshuqun@aliyun.com

*Contributed equally

Key words: primary hepatocellular carcinoma, cidan, Rhizoma Curcumae, cyclooxygenase-2, vascular endothelial growth factor the $\mathrm{C} 57 \mathrm{BL} / 6$ mice were significantly reduced in a time- and dose-dependent manner following cidan treatment $(\mathrm{P}<0.01)$. Cidan significantly reduced the cell viability of SMMC-7721 and CSQT-1 cells after four and five days when compared with the control $(\mathrm{P}<0.01)$. Furthermore, COX-2 and VEGF mRNA expression levels decreased following cidan treatment $(\mathrm{P}<0.01)$, and cidan treatment resulted in enhanced $\mathrm{G} 1$ and G2/M cell cycle arrest of CSQT-1 cells. Therefore, cidan effectively inhibited cell proliferation, reduced cell viability and downregulated COX-2 and VEGF expression levels in hepatoma cells.

\section{Introduction}

Primary liver cancer, also known as hepatocellular carcinoma (HCC), is the third leading cause of cancer-associated mortalities worldwide with $\sim 600,000$ cases reported annually (1). Chronic liver diseases, viral hepatitis and alcoholism, as well as dietary carcinogens, including aflatoxins and nitrosoamines, are known etiologies (2). In China, the incidence rate of HCC is particularly high due to the large number of patients with cirrhosis caused by chronic hepatitis following viral hepatitis $\mathrm{B}$ and $\mathrm{C}$ infections (3-5). Postoperative HCC recurrence rates are as high as 50\% (6) and at present, therapies primarily include surgery, local ablation, interventional and radiation therapies, in addition to medication. Superior curative effects may be achieved for HCC treatments when chemotherapy is combined with interventional traditional Chinese medicine (TCM), including Curcuma oil (microsphere) perfusion embolization. This intubation technique exhibited similar effects to western medicine using hepatic arterial transcatheter chemoembolization with regard to tumor size and survival time, but was also found to have a less severe effect on peripheral white blood cells and liver damage (7). A variety of TCMs combined with interventional hepatic artery chemotherapy embolization for toxicity reduction and enhancing the efficacy have been investigated for the treatment of HCC. There are two main advantages for TCM treatments of HCC: Firstly, the cytotoxic effects of the ingredients contained in the active natural anticancer drugs directly inhibit the growth of tumor cells (8-11), and secondly, the improvement of the immune system (12). Cidan capsules are a formula containing more than ten types of plant 
extracts, including Rhizoma Curcumae (19\%), Astragalus (19.6\%), Cremastra appendiculata (9.8\%), Salvia miltiorrhiza $(9.8 \%)$, hive $(9.8 \%)$ and Bombyx batryticatus $(9.8 \%)$ Cidan has been clinically used for $>10$ years as a safe and nontoxic antitumor drug. A number of studies have investigated the clinical application of TCMs for HCC $(13,14)$, demonstrating that $\beta$-elemene, which is present in Rhizoma Curcumae and the main component of cidan, may inhibit the proliferation of HepG2 cells in a time- and dose-dependent manner. The results indicated that $\beta$-elemene exhibited positive effects on apoptosis and induced the cell cycle arrest of HepG 2 cells in the G2/M phase, while Fas and Fas ligand expression levels were markedly increased $(15,16)$. In addition, a meta-analysis demonstrated that $\beta$-elemene improved the effect of lung cancer chemotherapy as an adjunctive treatment (14). In the present study, the outcomes of postoperative HCC medications with and without cidan were compared. In addition, the effects of cidan on human HCC cells transplanted in mice were investigated, as well as the effects of cidan on in vitro cultivated liver cancer cell proliferation and invasion capabilities and cyclooxygenase-2 (COX-2) and vascular endothelial growth factor (VEGF) expression levels.

\section{Patients and methods}

Patients. In total, 372 patients diagnosed with primary liver cancer via surgery and pathological examination were included in the study. A total of 92 patients comprised the cidan group, while the additional 280 patients were controls. The diagnosis and inclusion criteria were based on clinical and pathological observations, which were as follows: (i) AFP $\geq 400 \mu \mathrm{g} / \mathrm{ml}$ and exclusion of pregnancy, embryonic derived gonad tumors and active or metastatic liver cancer; could feel a swelling, hard, and have large nodular tumor of the liver or clear liver space occupying lesions by imaging examination; (ii) AFP $<400 \mu \mathrm{g} / \mathrm{ml}$ and exclusion of pregnancy, embryonic derived gonad tumors and active or metastatic liver cancer, but have the characteristics of liver space-occupying lesions by two types of imaging examinations, or have a positive expression of at least two liver cancer markers (DCP, GGTII, AFU, CA19-9 or others) and the characteristic of liver space-occupying lesions by one imaging examination; (iii) clear clinical appearance and positive extrahepatic metastasis lesions, including visible hemorrhagic ascites or cancer cells found in the lesion, and exclusion of metastatic liver cancer.

Treatments. The study was prospective, but non-randomized since the treatment group consisted of patients who agreed with the offered cidan treatment. In the treatment group, patients were postoperatively administered $1.35 \mathrm{~g}$ cidan capsules (Weida Pharmaceutical Co., Ltd., Beijing, China) three times a day in addition to the conventional liver protective drugs, polyene and phosphatidyl choline, whilst the control group received only conventional liver protective drugs without cidan. Administration of cidan capsules was continued for three months and long-term follow-up was continued with visits every two months. Patients in the two groups received routine treatments, including transarterial chemoembolization, when recurrence occurred. Any other anticancer drugs were discontinued in the treatment process.
Criteria of curative efficacy. Following the tumor resection, the two-year overall survival (OS) and disease-free survival (DFS) times of the patients were monitored. DFS was defined as the number of days from the first day following surgery until tumor recurrence. During the two-year follow-up period, all the patients routinely received general health examinations, blood, urinary and stool analyses, as well as liver and kidney function tests and cardiograms. Efficacy monitoring included: (i) Associated symptoms and signs; (ii) liver function tests analyzing the levels of total bilirubin, direct bilirubin, glutamic-pyruvic transaminase, glutamic oxalacetic transaminase, albumin, prealbumin and bile acid; (iii) enzyme analyses measuring the levels of ALP, GGT and lactic dehydrogenase isoenzyme; (iv) analysis of AFP; and (v) quality of life.

In vivo animal experiment. In total, 90 C57BL/6 mice (age, 5 weeks) were purchased from the Shanghai Laboratory Animal Center (Shanghai, China) and inoculated subcutaneously in the dorsal area with Hepa1-6 cells, diluted to $2 \times 10^{6}$ cells/mouse. After seven days, the mice with cancerous tumors of $>5 \mathrm{~mm}$ in diameter were divided into three groups, which included the blank control, cidan high-dose $(4.80 \mathrm{mg} / \mathrm{kg})$ and cidan low-dose $(1.92 \mathrm{mg} / \mathrm{kg})$ groups. The blank control group comprised 30 mice, while the Hepa1-6 inoculation model groups included 10 mice per group. Reagents were infused into the stomach once per day, while the blank control group were administered distilled water. At days 7, 14 and 21 following the start of treatment, the mice were sacrificed by cervical dislocation and the tumors were isolated and measured in order to calculate the growth inhibition ratios. The C57BL/6 mice were housed under specific pathogen-free conditions and animal treatments were conducted in accordance with the Principle of Laboratory Animal Care. The experimental procedures were performed with approval from the Committee of Experimental Animal Administration of the Second Military Medical University Laboratory (Shanghai, China) and written informed consent was provided by all the participating patients at admission.

Cell lines and culture conditions. Hepa1-6 cells were obtained from the Cell Bank of Shanghai Institute of Biochemistry and Cell Biology and cultured in high glucose Dulbecco's modified Eagle's medium supplemented with $10 \%$ heat-inactivated fetal bovine serum (FBS), $100 \mathrm{U} / \mathrm{ml}$ benzylpenicillin and $100 \mu \mathrm{g} / \mathrm{ml}$ streptomycin in a humidified atmosphere with $5 \%$ $\mathrm{CO}_{2}$ at $37^{\circ} \mathrm{C}$, as previously described (17). The human hepatoma cell lines, SMMC-7721 and CSQT-1, were established in the laboratory (18). Cells were grown in RPMI-1640 medium supplemented with $10 \%$ heat-inactivated FBS, $100 \mathrm{U} / \mathrm{ml}$ benzylpenicillin and $100 \mu \mathrm{g} / \mathrm{ml}$ streptomycin in a humidified atmosphere with $5 \% \mathrm{CO}_{2}$ at $37^{\circ} \mathrm{C}$. SMMC-7721 and CSQT-1 cells were seeded in $6-\mathrm{cm}$ culture plates and treated with various concentrations of cidan and the saline control (10, 20 and $40 \mu \mathrm{g} / \mathrm{ml}$ ) for different time courses. Each measurement was performed with three culture plates.

Cytotoxic activity assay. Cytotoxicity assays were performed according to the MTT method, as previously described (19). MTT was purchased from Sigma-Aldrich (St. Louis, MO, USA). Briefly, the cells were washed twice with phosphate-buffered 
saline (PBS) and cultured at a density of $5 \times 10^{4}$ cells $/ \mathrm{ml}$ in flat-bottomed 96-well microtiter plates in $100 \mu \mathrm{l}$ RPMI-1640 medium. Several dilutions of the tested compounds, in $100 \mu \mathrm{l}$ RPMI-1640 medium with 10\% FBS, were added to the wells. The final concentration of dimethyl sulfoxide used for MTT solubilization was $0.2 \%$ (v/v). Following incubation for $48 \mathrm{~h}$, $100 \mu \mathrm{l}$ medium was removed from each well and $20 \mu \mathrm{l}$ MTT solution $(5 \mathrm{mg} / \mathrm{ml}$ PBS) was added. Following incubation for $4 \mathrm{~h}$, the optical density was evaluated at $570 \mathrm{~nm}$. Growth inhibition rates were calculated as a percentage of the parallel negative controls. Each experiment was performed three times.

Cell Matrigel invasion assays. Tumor cell invasion through a reconstituted basement membrane (Matrigel; Sigma-Adrich, Carlsbad, CA, USA) was assayed as previously described (20). In 24-well Transwell cell culture chambers (Chemicon, Temecula, CA, USA), polycarbonate filters (pore size, $8 \mu \mathrm{m}$ ) were precoated with $1 \mu \mathrm{g}$ fibronectin on the lower surface, following which $5 \mu \mathrm{g} / 10 \mu \mathrm{l}$ Matrigel was applied to the upper surface of the filters. Uncoated wells were used as a negative control. The filters were first dried and washed in PBS, and following rehydration, the SMMC-7721 and CSQT-1 $\left(5 \times 10^{5}\right)$ cells were suspended in RPMI-1640 containing $0.1 \%$ bovine serum albumin. The filters were then pretreated with the tested samples for $30 \mathrm{~min}$ on ice, added to the upper chamber, and then incubated at $37^{\circ} \mathrm{C}$ for $12 \mathrm{~h}$. Following incubation, the cells that had invaded the lower chamber and attached to the lower surface of the filter were stained with calcein and quantified at excitation and emission wavelengths of 495 and $515 \mathrm{~nm}$, respectively. Four high-power fields were analyzed for each well.

Quantitative polymerase chain reaction ( $q P C R)$. Cells were collected at specified times and total RNA was extracted using TRIzol reagent (Invitrogen Life Technologies, Carlsbad, CA, USA), in accordance with the manufacturer's instructions. cDNA was constructed as a template to perform qPCR with COX-2, VEGF and $\beta$-actin specific primers. The qPCR analyses for VEGF and COX-2 transcription were performed in single microcapillary tubes using a LightCycler ${ }^{\mathrm{TM}}$ (Roche Diagnostics, Basel, Switzerland) and SYBR ${ }^{\circledR}$ Green Tag ReadyMix $^{\mathrm{TM}}$ (Sigma-Aldrich). Cycling parameters were optimized as follows: Denaturation at $94^{\circ} \mathrm{C}(10 \mathrm{sec})$, annealing at $55^{\circ} \mathrm{C}(5 \mathrm{sec})$, extension at $72^{\circ} \mathrm{C}(24 \mathrm{sec})$ and detection at $80^{\circ} \mathrm{C}$ (1 sec). Each microcapillary tube contained $7.1 \mu 1$ nuclease-free $\mathrm{H}_{2} \mathrm{O}, 10 \mu \mathrm{l}$ SYBR reagent, $0.5 \mu \mathrm{l}$ template cDNA, $1.6 \mu 1 \mathrm{MgCl}_{2}$ $(25 \mathrm{mM})$ and $0.8 \mu \mathrm{l}$ primer mixture $(25 \mathrm{pmol} / \mu \mathrm{l})$. Cycler software was used to quantify COX-2 and VEGF mRNA expression levels.

Cell cycle analysis using flow cytometery. Treated $(40 \mu \mathrm{g} / \mathrm{ml}$ cidan for $24 \mathrm{~h}$ ) and untreated CSQT-1 cells were harvested, washed with PBS and suspended $\left(10^{6} / \mathrm{ml}\right)$ in $1.5 \mathrm{ml}$ hypotonic fluorochromic solution $[50 \mathrm{mg} / \mathrm{ml}$ propidium iodide $(\mathrm{PI})$ in $0.1 \%$ sodium citrate plus $0.1 \%$ Triton X-100; Sigma-Aldrich] for $60 \mathrm{~min}$ at $48^{\circ} \mathrm{C}$ in the dark. PI fluorescence was analyzed using a FACScaliber flow cytometer (BD Biosciences, Franklin Lakes, NJ, USA) with ModFIT cell cycle analysis software version 2.01.2 (BD Biosciences). The experiments were repeated three times for each condition.
Statistical analysis. Data were analyzed using the unpaired t-test with two-tailed P-values or analysis of variance (for multiple comparisons) to calculate the statistical significance between the control and treatment groups. Levels of total bilirubin, direct bilirubin and albumin, the ratio of albumin to globin, prothrombin time, percentage of globin in protein electrophoresis and $\alpha$-L-fucosidase were compared between the groups using analysis of variance. The Wilcoxon rank sum test was used for comparisons of AFP, carcinoembryonic antigen, carbohydrate antigen 19-9, alanine aminotransferase, aspartate aminotransferase, ALP and hepatitis B virus-DNA/1,000 between the groups. Additional categorical variables were compared between the groups using Fisher's exact test. The results are presented as the mean \pm standard error of the mean, and $\mathrm{P}<0.05$ was considered to indicate a statistically significant difference.

\section{Results}

No significant variation in the basic characteristics of the cidan and control patients. Although statistically significant differences [AFP, hepatitis B e antigen positive, anti-hepatitis $\mathrm{C}$ virus positive and portal clamping duration] were observed in the basic characteristics between the two groups prior to surgery, the majority of the parameters did not significantly vary (Table I). The pathological data at day 2 following surgery indicated that there were no statistically significant differences between the cidan treatment and control groups, despite a reduction in the occurrence of incomplete tumor capsules in the cidan treatment group (Table II).

Differences in the OS and DFS times between the cidan and control groups. The two-year OS rate of the patients that received postoperative cidan as adjuvant therapy was $77 \%$, while the OS rate of the solely hepatoprotective drug treatment group was $58 \%$ (Table III; $\mathrm{P}=0.0031$ ). The two-year DFS rate in the cidan treatment group was $36 \%$, while in the control group, the DFS was $24 \%$ (Table IV; $\mathrm{P}=0.006$ ). A Cox regression model was used to analyze the effect of postoperative adjunctive cidan medication on the OS and DFS rates of patients with HCC following surgery (Figs. 1 and 2), which demonstrated that the use of adjuvant cidan therapy reduced tumor recurrence and improved the survival times.

Anticancer effect of cidan in the Hepal-6 implanted male C57BL/6 mouse model. In order to further analyze the effect of cidan on hepatic tumor cells, a mouse HCC model was

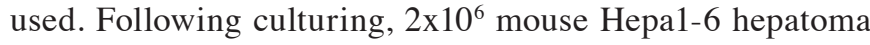
cells were injected into the subcutaneous tissue of C57BL/6 mice. After seven days, the mice were treated with high $(4.80 \mathrm{mg} / \mathrm{kg})$ or low $(1.92 \mathrm{mg} / \mathrm{kg})$ doses of cidan, or with distilled water as a control. The tumors were removed from the mice after one, two or three weeks following the start of treatment. The results revealed that the average weight of the tumors after two weeks of high-dose cidan treatment was $50 \%$ lower when compared with the control group. Low-dose cidan treatment reduced the tumor size to a lesser extent when compared with the high-concentration cidan treatment. The same trend was observed after three weeks of treatment (Table V). 
Table I. Preoperative comparison of patient characteristics between the two treatment groups.

\begin{tabular}{|c|c|c|c|}
\hline Variable & Control group $(\mathrm{n}=280)$ & Treatment group $(\mathrm{n}=92)$ & P-value \\
\hline Age, years & $49.16 \pm 10.824$ & $50.64 \pm 10.553$ & 0.252 \\
\hline Male, n (\%) & $226(80.7)$ & $84(91.3)$ & 0.018 \\
\hline Female, n (\%) & $54(19.3)$ & $8(8.7)$ & \\
\hline $\mathrm{AFP}, \mu \mathrm{g} / 1$ & $559.413 \pm 554.8254$ & $367.926 \pm 501.8287$ & 0.002 \\
\hline AFU, U/1 & $33.614 \pm 1.0493$ & $33.391 \pm 0.9514$ & 0.866 \\
\hline ALP, U/1 & $114.964 \pm 101.4081$ & $107.315 \pm 58.3713$ & 0.493 \\
\hline ALT, U/1 & $50.748 \pm 50.7809$ & $58.627 \pm 122.0881$ & 0.382 \\
\hline AST, U/1 & $54.581 \pm 46.0912$ & $64.865 \pm 140.9475$ & 0.289 \\
\hline CA19-9, U/ml & $38.078 \pm 84.1362$ & $25.833 \pm 22.6981$ & 0.169 \\
\hline $\mathrm{CEA}, \mu \mathrm{g} / 1$ & $3.201 \pm 6.7797$ & $3.242 \pm 3.7395$ & 0.956 \\
\hline GGT, U/1 & $116.793 \pm 120.5559$ & $123.686 \pm 126.3800$ & 0.639 \\
\hline Albumin, $\mathrm{g} / \mathrm{l}$ & $41.173 \pm 3.9815$ & $41.974 \pm 4.1169$ & 0.098 \\
\hline Ratio of albumin and globin & $1.341 \pm 0.2238$ & $1.384 \pm 0.2637$ & 0.131 \\
\hline Size of tumor, $\mathrm{cm}$ & $9.1350 \pm 4.74699$ & $9.2489 \pm 4.91545$ & 0.843 \\
\hline Prealbumin, mg/l & $220.018 \pm 57.9002$ & $228.902 \pm 56.9922$ & 0.201 \\
\hline Total bilirubin, $\mu \mathrm{mol} / 1$ & $15.426 \pm 6.4219$ & $14.754 \pm 5.4803$ & 0.368 \\
\hline Direct bilirubin, $\mu \mathrm{mol} / \mathrm{l}$ & $5.730 \pm 3.0187$ & $5.351 \pm 2.1050$ & 0.265 \\
\hline Prothrombin time, sec & $12.202 \pm .9329$ & $12.065 \pm .9718$ & 0.228 \\
\hline Hepatic portal blocking time, min & $16.98 \pm 11.048$ & $13.60 \pm 7.507$ & 0.001 \\
\hline Intraoperative bleeding, ml & $463.11 \pm 616.957$ & $373.37 \pm 412.807$ & 0.115 \\
\hline Intraoperative blood transfusion, $\mathrm{ml}$ & $358.07 \pm 1479.115$ & $158.70 \pm 460.328$ & 0.204 \\
\hline Globin in protein electrophoresis, $\%$ & $20.3164 \pm 4.29137$ & $20.1241 \pm 4.66117$ & 0.715 \\
\hline \multicolumn{4}{|l|}{ Anti-HBcAg, n (\%) } \\
\hline Positive & $269(96.1)$ & $91(98.9)$ & 0.308 \\
\hline Negative & $11(3.9)$ & $1(1.1)$ & \\
\hline \multicolumn{4}{|l|}{ Anti-HBeAg, n (\%) } \\
\hline Positive & $175(62.5)$ & $62(67.4)$ & 0.581 \\
\hline Negative & $105(37.5)$ & $30(32.6)$ & \\
\hline \multicolumn{4}{|l|}{$\mathrm{HBeAg}, \mathrm{n}(\%)$} \\
\hline Positive & $108(38.6)$ & $24(26.1)$ & 0.030 \\
\hline Negative & $172(61.4)$ & $68(73.9)$ & \\
\hline \multicolumn{4}{|l|}{ Anti-HCV, n (\%) } \\
\hline Positive & $4(1.4)$ & $6(6.5)$ & 0.017 \\
\hline Negative & $276(98.6)$ & $86(93.5)$ & \\
\hline \multicolumn{4}{|l|}{ Microscopic vascular invasion, n (\%) } \\
\hline Yes & $53(18.9)$ & $15(16.3)$ & 0.572 \\
\hline No & $227(81.1)$ & $77(83.7)$ & \\
\hline \multicolumn{4}{|l|}{ Portal vein tumor thrombus, n (\%) } \\
\hline Yes & $38(13.6)$ & $15(16.3)$ & 0.515 \\
\hline No & $242(86.4)$ & $77(83.7)$ & \\
\hline \multicolumn{4}{|l|}{ Satellite nodules, n (\%) } \\
\hline Yes & $70(25.0)$ & $16(17.4)$ & 0.133 \\
\hline No & $210(75.0)$ & $76(82.6)$ & \\
\hline \multicolumn{4}{|l|}{ Tumor size, n (\%) } \\
\hline$\leq 5 \mathrm{~cm}$ & $69(24.6)$ & $25(27.2)$ & 0.628 \\
\hline$>5 \mathrm{~cm}$ & $211(75.4)$ & $67(72.8)$ & \\
\hline \multicolumn{4}{|l|}{ Tumor size, n (\%) } \\
\hline$\leq 10 \mathrm{~cm}$ & $176(62.9)$ & $54(58.7)$ & 0.476 \\
\hline$>10 \mathrm{~cm}$ & $104(37.1)$ & $38(41.3)$ & \\
\hline \multicolumn{4}{|l|}{ Tumor number, n (\%) } \\
\hline Single tumor & $231(82.5)$ & $83(90.2)$ & 0.077 \\
\hline Multiple tumors & $49(17.5)$ & $9(9.8)$ & \\
\hline
\end{tabular}


Table I. Continued.

\begin{tabular}{lcc}
\hline Variable & Control group $(\mathrm{n}=280)$ & Treatment group $(\mathrm{n}=92)$ \\
\hline $\begin{array}{l}\text { Rupture of tumor, } \mathrm{n}(\%) \\
\text { Yes }\end{array}$ & $5(1.8)$ & $3(3.3)$ \\
No & $275(98.2)$ & $89(96.7)$
\end{tabular}

AFP, $\alpha$-1-fetoprotein; AFU, $\alpha$-L-fucosidase; ALP, alkaline phosphatase; ALT, alanine aminotransferase; AST, aspartate aminotransferase; CA19-9, carbohydrate antigen 19-9; CEA, carcinoembryonic antigen; GGT, $\gamma$-glutamyl transferase; HBcAg, hepatitis B c antigen; HBeAg, hepatitis $\mathrm{B}$ e antigen; $\mathrm{HCV}$, hepatitis $\mathrm{C}$ virus.

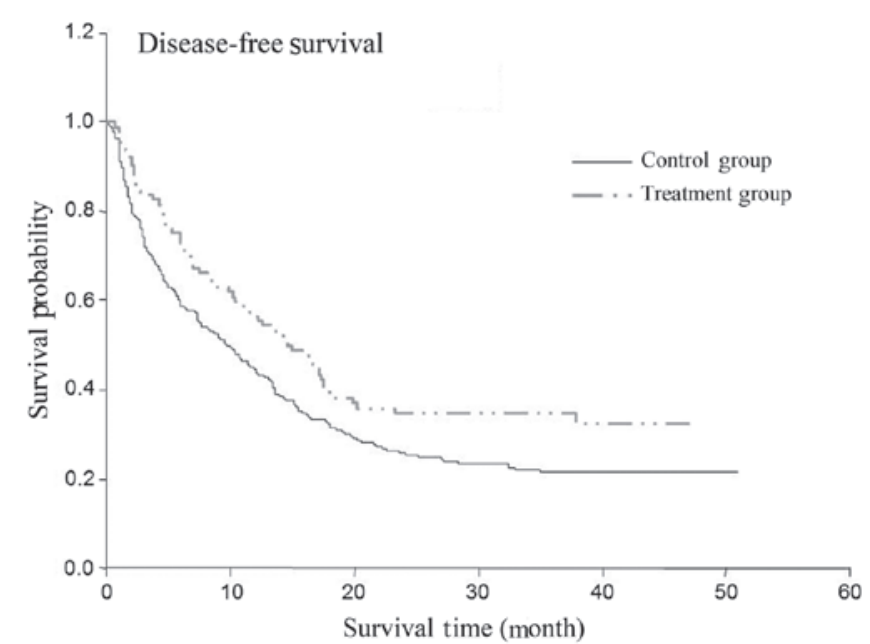

Figure 1. Comparison of the postoperative OS rates of patients with HCC treated with liver-protection drugs only (control group) or with liver-protection drugs and cidan (treatment group). HCC, hepatocellular carcinoma; DFS, Disease-free survival.

Cidan inhibits COX-2 and VEGF expression, is toxic in the long-term and inhibits the cell invasion capacities of hepatic tumor cells. SMMC-7721 tumor cells were cultured and treated with cidan, following which the transcription levels of COX-2 and VEGF were analyzed and changes in the tumor cell growth rates were determined. As shown in Fig. 3, the mRNA expression levels of COX-2 and VEGF in the cells treated with cidan were significantly decreased compared with the control. MTT cytotoxicity assays were then performed to determine the effect of cidan on the viability of SMMC-7721 and CSQT-1 cell lines. Cidan exhibited statistically significant cytotoxic effects on SMMC-7721 cells after four and five days $(\mathrm{P}<0.01)$, and on CSQT-1 cells after five days $(\mathrm{P}<0.01)$, when applied at a dosage of $40 \mu \mathrm{g} / \mathrm{ml}$ (Fig. 4). In addition, Matrigel cell invasion capacity analysis using a Transwell chamber assay revealed that cidan $(40 \mu \mathrm{g} / \mathrm{ml})$ significantly suppressed SMMC-7721 $(\mathrm{P}<0.01)$ and CSTQ $(\mathrm{P}<0.001)$ cell invasion through Matrigel-coated filters (Fig. 5).

Cidan induces pronounced G2/M cell cycle arrest in CSQT-1 cells. As shown in Fig. 6, $40 \mu \mathrm{g} / \mathrm{ml}$ cidan application for $24 \mathrm{~h}$ increased the number of cells in the G1 and G2/M cell cycle phases. In addition, the number of cells in the $\mathrm{S}$ cell cycle phase was reduced, indicating that the hepatic cancer cell proliferation rate was reduced.

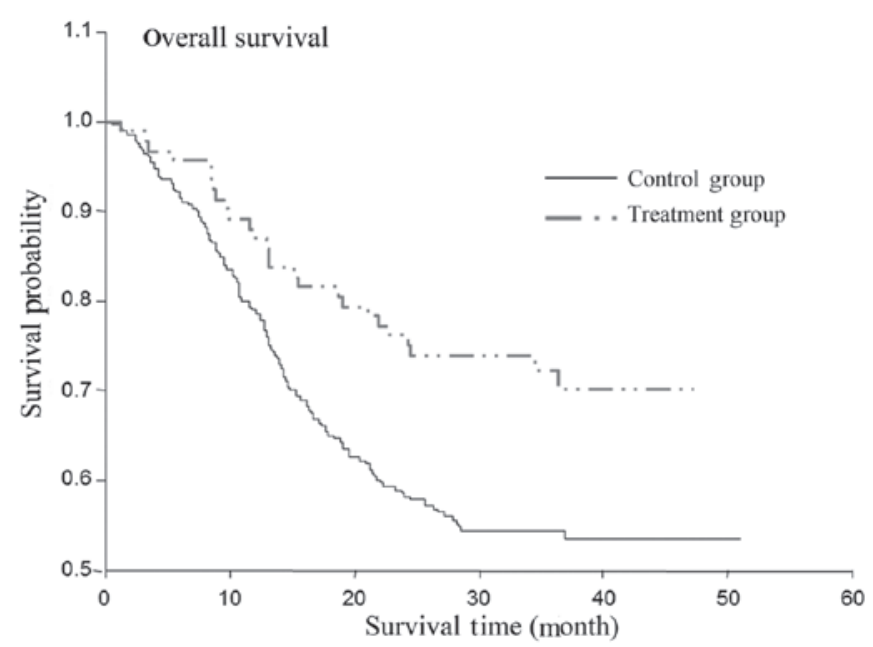

Figure 2. Comparison of the postoperative DFS times of patients with HCC treated with liver-protection drugs only (control group) or with liver-protection drugs and cidan (treatment group). HCC, hepatocellular carcinoma; OS, overall survival.

Therefore, the results revealed that cidan positively affected the DFS and OS rates of patients with HCC. Cidan also reduced mouse model hepatic tumor cell growth in a dose-dependent manner, reduced COX-2 and VEGF expression levels and exhibited cytotoxic effects in hepatic cancer cells. In addition, cidan induced G2/M and G1 cell cycle arrests in vitro.

\section{Discussion}

In the present study, cidan was demonstrated to improve the postoperative DFS and OS rates in patients with HCC (Figs. 1 and 2), as well as reduce the growth of subcutaneously implanted HCC tumors in mouse models in a dose-dependent manner (Table V). Cidan controls the progression of HCC effectively via a number of oxidative stress and inflammatory reactions, where several associated cytokines and signaling pathways have been confirmed to affect the pathogenesis of HCC $(21,22)$. A number of phytochemicals exhibit anti-inflammatory effects, such as curcumin, a polyphenolic compound derived from rhizomes of Curcuma. Curcumin mediates the suppression of nuclear factor- $\kappa \mathrm{B}(\mathrm{NF}-\kappa \mathrm{B})$, the master switch in the inflammatory cascade (23). NF- $\mathrm{NB}$ activation is known to regulate several key inflammatory mediators, including cytokines, chemo- 
Table II. Comparison of postoperative pathological determinations between the two groups of patients.

\begin{tabular}{|c|c|c|c|}
\hline Variable & Liver protection group & Cidan group & P-value \\
\hline \multicolumn{4}{|l|}{ Cell type, n (\%) } \\
\hline Coarse trabecular & $190(67.9)$ & $54(58.7)$ & \\
\hline Coarse trabecular-pseudo ductular & $2(0.7)$ & $1(1.1)$ & \\
\hline Coarse trabecular-hyaline & $3(1.1)$ & - & \\
\hline Super fat & $1(0.4)$ & - & \\
\hline Mixed & $2(0.7)$ & - & \\
\hline Pseudo ductular & $4(1.4)$ & $8(8.7)$ & \\
\hline Others & $2(0.7)$ & - & \\
\hline Hyaline & $8(2.9)$ & $2(2.2)$ & \\
\hline In groups and sheets & $8(2.9)$ & $10(10.9)$ & \\
\hline In groups and sheets-hyaline & - & $1(1.1)$ & \\
\hline Fine trabecular & $56(20.0)$ & $16(17.4)$ & \\
\hline Fine trabecular-super fat & $1(0.4)$ & - & \\
\hline Fine trabecular-pseudo ductular & $3(1.1)$ & - & \\
\hline \multicolumn{4}{|l|}{ Tumor capsule, n (\%) } \\
\hline Total & $280(100.0)$ & $92(100.0)$ & \\
\hline Incomplete & $89(31.8)$ & $19(20.7)$ & 0.0119 \\
\hline Complete & $95(33.9)$ & $47(51.1)$ & 0.0598 \\
\hline Without & $96(34.3)$ & $26(28.3)$ & 0.4658 \\
\hline \multicolumn{4}{|l|}{ Satellite nodules, n (\%) } \\
\hline Total & $280(100.0)$ & $92(100.0)$ & \\
\hline Without & $210(75.0)$ & $76(82.6)$ & 0.1547 \\
\hline With & $70(25.0)$ & $16(17.4)$ & 0.2609 \\
\hline \multicolumn{4}{|l|}{ Microscopic vascular invasion, $\mathrm{n}(\%)$} \\
\hline Total & $280(100.0)$ & $92(100.0)$ & \\
\hline Without & $227(81.1)$ & $77(83.7)$ & 0.6427 \\
\hline With & $53(18.9)$ & $15(16.3)$ & 0.7587 \\
\hline \multicolumn{4}{|l|}{ Cell grading, n (\%) } \\
\hline Total & $280(100.0)$ & $92(100.0)$ & \\
\hline I & $1(0.4)$ & $1(1.1)$ & 0.5843 \\
\hline II & $63(22.5)$ & $22(23.9)$ & 0.8896 \\
\hline III & $214(76.4)$ & $68(73.9)$ & 0.9269 \\
\hline IV & $2(0.7)$ & $1(1.1)$ & 0.5759 \\
\hline
\end{tabular}

P-value, Liver protection vs.Cidan group.

Table III. Effect of antitumor medication (cidan) on the prognosis of patients (OS rate).

\begin{tabular}{lcccc}
\hline Subgroup & HR & $95 \%$ CI lower & $95 \%$ CI upper & P-value \\
\hline Cidan (+) vs. (-) & 0.476 & 0.292 & 0.778 & 0.0031
\end{tabular}

Results were determined using a Cox regression model. HR, hazard ratio; CI, confidence interval; OS, overall survival.

Table IV. Effect of antitumor medication (cidan) on the prognosis of patients (DFS time).

\begin{tabular}{|c|c|c|c|c|}
\hline Subgroup & HR & 95\% CI lower & $95 \%$ CI upper & P-value \\
\hline Cidan (+) vs. (-) & 0.646 & 0.473 & 0.882 & 0.0060 \\
\hline
\end{tabular}

Results were determined using a Cox regression model. HR, hazard ratio; CI, confidence interval; DFS, disease-free survival. 
Table V. Inhibition of Hepa1-6 cell xenograft tumor growth in mice by cidan treatment.

\begin{tabular}{|c|c|c|c|c|c|}
\hline Treatment & $\begin{array}{c}\text { Cidan dose, } \\
\mathrm{mg} / \mathrm{kg}\end{array}$ & Animals, $\mathrm{n}$ & Animal weight, $g$ & $\begin{array}{c}\text { Tumor } \\
\text { weight, g }\end{array}$ & Inhibition ratio, $\%$ \\
\hline \multicolumn{6}{|l|}{1 week } \\
\hline Control & - & 10 & $28.8 \pm 3.5$ & $2.0 \pm 0.7$ & - \\
\hline Cidan low & 1.92 & 10 & $28.7 \pm 2.3$ & $1.8 \pm 0.7$ & 9.0 \\
\hline Cidan high & 4.80 & 10 & $28.2 \pm 4.2$ & $1.6 \pm 0.5^{\mathrm{a}}$ & 22.0 \\
\hline \multicolumn{6}{|l|}{2 weeks } \\
\hline Control & - & 10 & $29.0 \pm 3.1$ & $2.2 \pm 0.8$ & - \\
\hline Cidan low & 1.92 & 10 & $27.4 \pm 2.5$ & $2.1 \pm 0.7$ & 15.4 \\
\hline Cidan high & 4.80 & 10 & $27.8 \pm 4.3$ & $1.1 \pm 0.3^{\mathrm{b}}$ & 30.2 \\
\hline \multicolumn{6}{|l|}{3 weeks } \\
\hline Control & - & 10 & $28.2 \pm 3.0$ & $3.2 \pm 0.9$ & - \\
\hline Cidan low & 1.92 & 10 & $28.4 \pm 2.3$ & $1.8 \pm 0.5$ & 18.0 \\
\hline Cidan high & 4.80 & 10 & $27.8 \pm 4.2$ & $1.1 \pm 0.4^{\mathrm{b}}$ & 35.0 \\
\hline
\end{tabular}

${ }^{\mathrm{a}} \mathrm{P}<0.05$ and ${ }^{\mathrm{b}} \mathrm{P}<0.01$, vs. control.
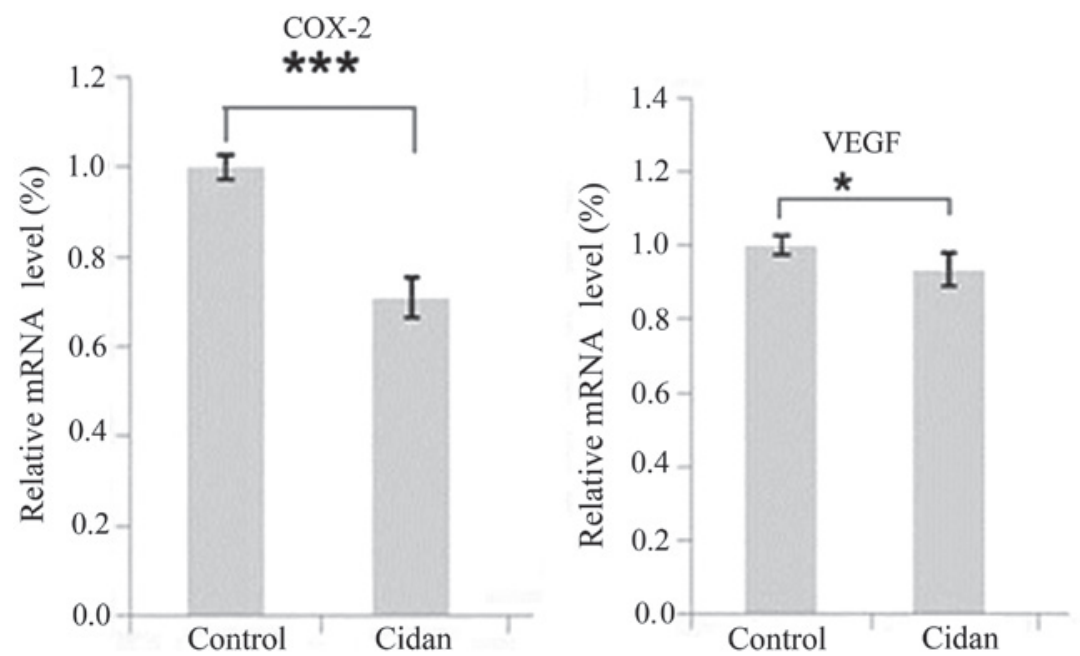

Figure 3. COX-2 and VEGF mRNA expression levels in SMMC-7721 cells following treatment with cidan. ${ }^{* * *} \mathrm{P}<0.001$ and ${ }^{*} \mathrm{P}<0.05$, vs. control group (saline). COX-2, cyclooxygenase-2; VEGF, vascular endothelial growth factor.
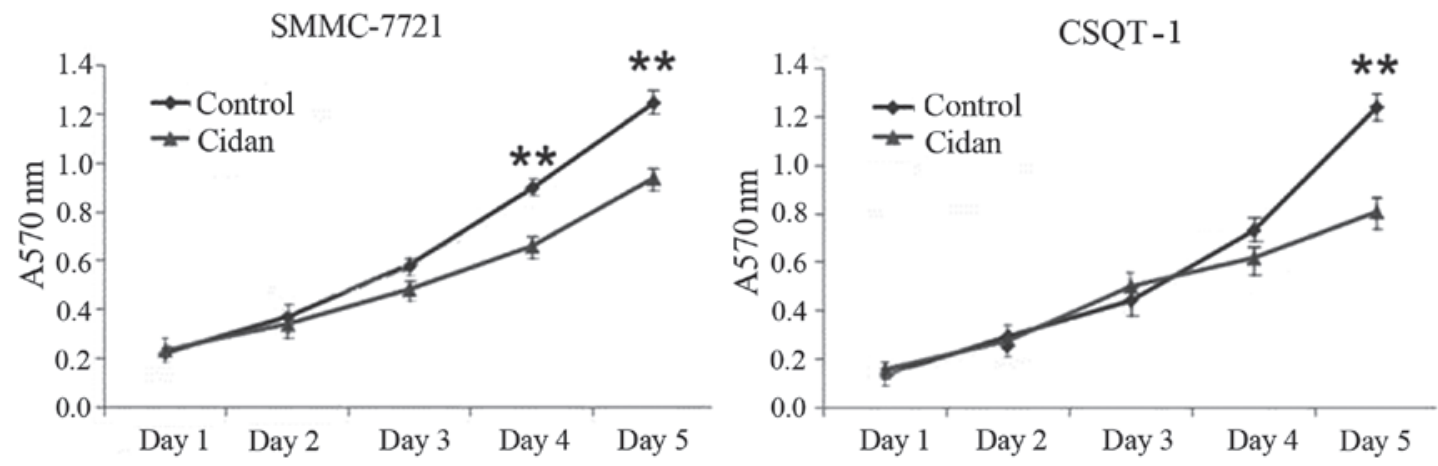

Figure 4. In vitro cytotoxic activity of cidan in human tumor cell lines. ${ }^{* *} \mathrm{P}<0.01$, vs. Cidan group (saline).

kines and kinases, which have been shown to play critical roles in the pathogenesis of the majority of chronic illnesses (24) The curcumin-mediated attenuation of the NF- $\mathrm{NB}$-activated inflammatory cascade is a critical mechanism of its therapeutic effects (25). Although cidan is the most widely known and effective curcuminoid present in China, this drug also 

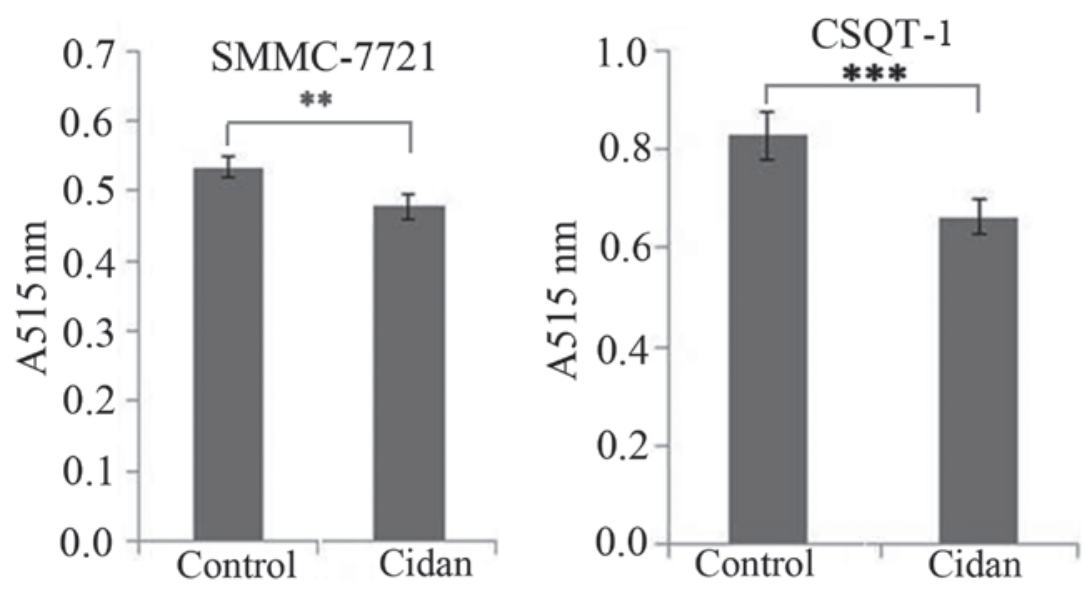

Figure 5. Inhibition of Matrigel cell invasion. SMMC-7721 and CSQT-1 cells were incubated with cidan-containing medium for $12 \mathrm{~h} .{ }^{* *} \mathrm{P}<0.01$ and ${ }^{* * *} \mathrm{P}<0.001$, cidan treatment group vs. control group (saline).

A

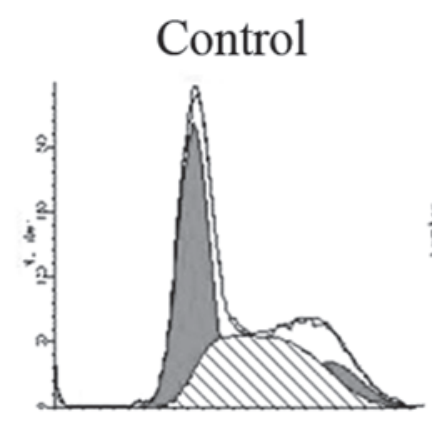

Cidan

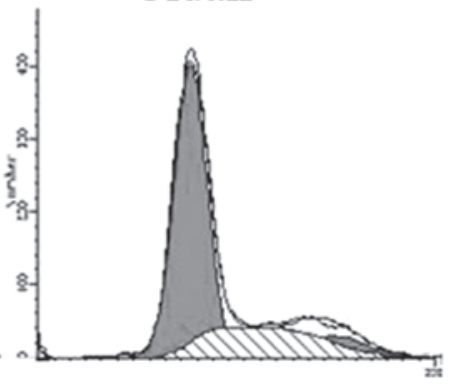

B

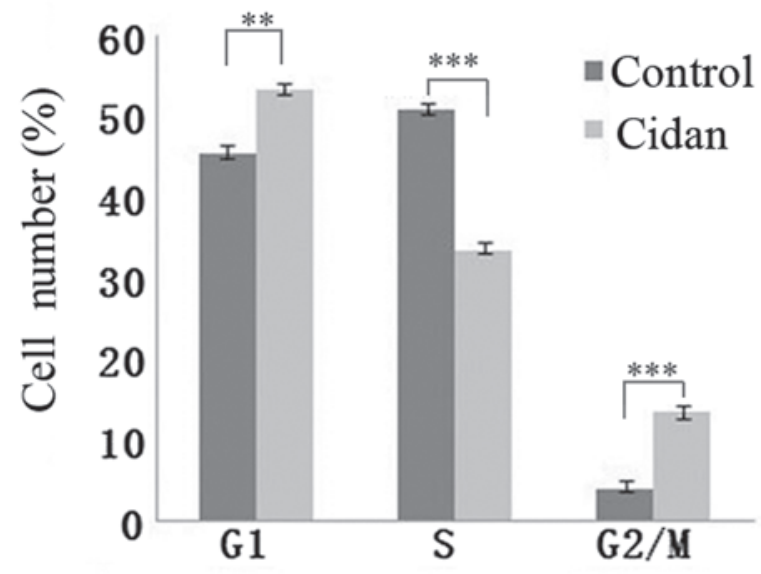

C

\begin{tabular}{cccc}
\hline Group & G1 (\%) & S (\%) & G2/M(\%) \\
\hline \multirow{3}{*}{ Control } & 45.54 & 50.71 & 3.74 \\
& 44.68 & 51.3 & 4.01 \\
& 45.83 & 50.2 & 3.96 \\
\hline \multirow{3}{*}{ Cidan } & 53.34 & 33.72 & 12.94 \\
& 53.38 & 33.74 & 12.88 \\
& 52.8 & 33.01 & 14.19 \\
\hline
\end{tabular}

Figure 6. Flow cytometric analysis of CSQT-1 cells following $24 \mathrm{~h}$ incubation with $40 \mu \mathrm{g} / \mathrm{ml}$ cidan or saline (control). (A) Representative flow cytometry images; (B) percentage chart and (C) numerical analysis of the cells in the various cell cycle stages. ${ }^{* *} \mathrm{P}<0.01$ and ${ }^{* * * *} \mathrm{P}<0.001$, vs. control cells (saline treatment).

contains more than three additional polyphenolic curcuminoids. Elemene is the anticancer component extracted from Rhizoma Curcumae, which has been demonstrated to have an anticancer effect by inducing apoptosis in tumor cells $(26,27)$. Recently, an additional study demonstrated that curcumin induced $\mathrm{G} 2 / \mathrm{M}$ cell cycle arrest via targeting the 
anaphase-promoting complex/cyclosome protein, $\mathrm{Cdc} 27$, and inducing enhanced apoptosis rates (28). The results of the present study were in accordance with these observations, and marked G2/M phase cell cycle arrest was observed in the CSQT-1 cells following incubation with cidan (Fig. 6). In addition to the enhanced G2/M cell cycle arrest of CSQT-1 cells, cidan was shown to inhibit COX-2 and VEGF expression levels and prevent hepatic cancer cell invasion activity (Figs. 3 and 5). These observations indicated that there was a synergistic cell growth inhibition of SMMC-7721 and CSQT-1 cells, accompanied with an increase in apoptosis rates and a decrease in $\mathrm{NF}-\kappa \mathrm{B}$ activation with concomitant lowering of COX-2 expression levels, as demonstrated in a previous study (29). Tanshinone, the effective component extracted from Salvia miltiorrhiza, is also found in cidan and has known anticancer properties. This compound has been demonstrated to dissolve fibrin wrapped on the surface of cancer cells, increase the immunogenicity of tumors, induce cell differentiation and gradually reduce the malignancy of cancer cells (30). Furthermore, cidan capsules contain Brucea javanica oil, extracted from Brucea javanica, which has been shown to induce apoptosis and decrease cell proliferation; thus, demonstrating favorable antitumor activity (31). Additional ingredients include Cirrhopetalanthrin, a type of chemical composition extracted from Cremastrae appendiculata, which exhibits anticancer activity by inhibiting mitosis, and Astragalus, which promotes the body to monitor tumor cells and produce interferon, increasing lymphokine-activated killer and natural killer cell activity and strengthening the phagocytic function of the reticuloendothelial system to kill cancer cells (32). Furthermore, a low therapeutic cidan concentration in patients has been cited as a reason for the lack of sufficient success in clinical trials. In the present in vivo study, this hypothesis was supported since tumor growth was shown to diminish in the mouse model in a dose-dependent manner (Table V).

In conclusion, the present study demonstrated that cidan effectively inhibited proliferation and was toxic to hepatoma cells. Furthermore, COX-2 and VEGF expression levels were found to be downregulated following cidan administration. Thus, cidan therapy may effectively reduce tumor recurrence and improve the OS time when applied as postoperative treatment for HCC. However, further studies are required to clarify the exact mechanisms involved in the antitumor effects of cidan, with particular focus on the activity of the individual ingredients.

\section{Acknowledgements}

The authors thank Chao $\mathrm{Xu}$ from Shanghai Changzheng Hospital for their assistance and support. The study was supported by grants from the China National Funds for Distinguished Young Scientists (no. 81125018), the National Natural Science Fund (no. 81101511), the New Excellent Talents Program (no. XBR2011025), General Program from Shanghai Municipal Health Bureau (no. 20124301), the New Excellent Talents Program (no. 10XD1405800) and the Shanghai Rising-star Program from the Shanghai Science and Technology Committee (no. 13QA1404900) and National Major Scientific and Technological Special Project for 'Significant New Drugs Development' during the Twelfth Five-year Plan Period (no. 2013ZX09104006).

\section{References}

1. Parkin DM, Bray F, Ferlay J and Pisani P: Global cancer statistics, 2002. CA Cancer J Clin 55: 74-108, 2005.

2. Darvesh AS, Aggarwal BB and Bishayee A: Curcumin and liver cancer: a review. Curr Pharm Biotechnol 13: 218-228, 2012.

3. Li W, Gao Z, Yang C, et al: The estimation of prevalence, incidence, and residual risk of transfusion-transmitted human hepatitis B infection from blood donated at the Anhui blood center, China, from 2009 to 2011. PloS One 8: e73472, 2013.

4. Su Y, Norris JL, Zang C, Peng Z and Wang N: Incidence of hepatitis $\mathrm{C}$ virus infection in patients on hemodialysis: a systematic review and meta-analysis. Hemodial Int 17: 532-541, 2013.

5. Chen WQ, Zheng RS and Zhang SW: Liver cancer incidence and mortality in China, 2009. Chin J Cancer 32: 162-169, 2013.

6. Llovet JM, Burroughs A and Bruix J: Hepatocellular carcinoma. Lancet 362: 1907-1917, 2003.

7. Cheng JH, Chang G and Wu WY: A controlled clinical study between hepatic arterial infusion with embolized curcuma aromatic oil and chemical drugs in treating primary liver cancer. Zhongguo Zhong Xi Yi Jie He Za Zhi 21: 165-167, 2001 (In Chinese).

8. Wang WX, Li TX, Ma H, et al: Tumoral cytotoxic and antioxidative phenylpropanoid glycosides in Smilax riparia A. DC. J Ethnopharmacol 149: 527-532, 2013.

9. Liang QL, Dai CC, Jiang JH, Tang YP and Duan JA: A new cytotoxic casbane diterpene from Euphorbia pekinensis. Fitoterapia 80: 514-516, 2009.

10. Fang R, Houghton PJ and Hylands PJ: Cytotoxic effects of compounds from Iris tectorum on human cancer cell lines. J Ethnopharmacol 118: 257-263, 2008.

11. Duan JA, Wang L, Qian S, Su S and Tang Y: A new cytotoxic prenylated dihydrobenzofuran derivative and other chemical constituents from the rhizomes of Atractylodes lancea DC. Arch Pharm Res 31: 965-969, 2008.

12. Lin H, Liu J and Zhang Y: Developments in cancer prevention and treatment using traditional Chinese medicine. Front Med 5: 127-133, 2011.

13. Dong HY, Shao JW, Wang T, Guo YH and Yan LY: Effects on the activities and mRNA expression of CYP3A in rat's liver by four kinds of extracts from anti-cancer traditional Chinese medicines. Zhong Yao Cai 31: 68-71, 2008 (In Chinese).

14. Wang B, Peng XX, Sun R, et al: Systematic review of $\beta$-elemene injection as adjunctive treatment for lung cancer. Chin J Integr Med 18: 813-823, 2012

15. Dai ZJ, Tang W, Lu WF, et al: Antiproliferative and apoptotic effects of $\beta$-elemene on human hepatoma HepG2 cells. Cancer Cell Int 13: 27, 2013.

16. Lu JJ, Dang YY, Huang M, Xu WS, Chen XP, and Wang YT: Anti-cancer properties of terpenoids isolated from Rhizoma Curcumae - a review. J Ethnopharmacol 143: 406-411, 2012.

17. Wang Q, Luan W, Goz V, Burakoff SJ and Hiotis SP: Non-invasive in vivo imaging for liver tumour progression using an orthotopic hepatocellular carcinoma model in immunocompetent mice. Liver Int 31: 1200-1208, 2011.

18. Hu HS, Cheng SQ, Shi J, et al: Establishment and characterization of a human hepatocellular carcinoma cell line CSQT-1 derived from portal vein tumor thrombus. Di Er Jun Yi Da Xue Xue Bao 30: 1-4, 2009.

19. Carmichael J, DeGraff WG, Gazdar AF, Minna JD and Mitchell JB: Evaluation of a tetrazolium-based semiautomated colorimetric assay: assessment of chemosensitivity testing. Cancer Res 47: 936-942, 1987.

20. Bauer JS, Schreiner CL, Giancotti FG, Ruoslahti E and Juliano RL: Motility of fibronectin receptor-deficient cells on fibronectin and vitronectin: collaborative interactions among integrins. J Cell Biol 116: 477-487, 1992.

21. Pang R, Tse E and Poon RT: Molecular pathways in hepatocellular carcinoma. Cancer Lett 240: 157-169, 2006.

22. Wong CM and Ng IO: Molecular pathogenesis of hepatocellular carcinoma. Liver Int 28: 160-174, 2008.

23. Singh S and Aggarwal BB: Activation of transcription factor NF-kappa B is suppressed by curcumin (diferuloylmethane) [corrected]. J Biol Chem 270: 24995-25000, 1995. 
24. Libby P: Inflammatory mechanisms: the molecular basis of inflammation and disease. Nutr Rev 65: S140-S146, 2007.

25. Aggarwal BB, Kunnumakkara AB, Harikumar KB, Tharakan ST, Sung B and Anand P: Potential of spice-derived phytochemicals for cancer prevention. Planta Med 74: 1560-1569, 2008.

26. Lu JJ, Dang YY, Huang M, Xu WS, Chen XP and Wang YT: Anti-cancer properties of terpenoids isolated from Rhizoma Curcumae - a review. J Ethnopharmacol 143: 406-411, 2012.

27. Xu WS, Dang YY, Guo JJ, et al: Furanodiene induces endoplasmic reticulum stress and presents antiproliferative activities in lung cancer cells. Evid Based Complement Alternat Med 2012: 426521, 2012.

28. LeeSJandLanghans SA:Anaphase-promoting complex/cyclosome protein $\mathrm{Cdc} 27$ is a target for curcumin-induced cell cycle arrest and apoptosis. BMC Cancer 12: 44, 2012.
29. Notarbartolo M, Poma P, Perri D, Dusonchet L, Cervello M and D'Alessandro N: Antitumor effects of curcumin, alone or in combination with cisplatin or doxorubicin, on human hepatic cancer cells. Analysis of their possible relationship to changes in NF- $\mathrm{KB}$ activation levels and in IAP gene expression. Cancer Lett 224: 53-65, 2005.

30. Tung YT, Chen HL, Lee CY, et al: Active component of Danshen (Salvia miltiorrhiza Bunge), tanshinone I, attenuates lung tumorigenesis via inhibitions of VEGF, cyclin A, and cyclin B expressions. Evid Based Complement Alternat Med 2013: 319247, 2013.

31. Nie YL, Liu KX, Mao XY, Li YL, Li J and Zhang MM: Effect of injection of Brucea javanica oil emulsion plus chemoradiotherapy for lung cancer: a review of clinical evidence. J Evid Based Med 5: 216-225, 2012.

32. Li XY: Immunomodulating components from chinese medicines. Pharm Biol 38 (Suppl 1): 33-40, 2000. 